\title{
Electronic Equipment Reliability
}


Other titles in Electrical and Electronic Engineering

W. Gosling: A First Course in Applied Electronics

B. A. Gregory: An Introduction to Electrical Instrumentation

Paul A. Lynn: An Introduction to the Analysis and Processing of Signals

A. G. Martin and F. W. Stephenson: Linear Microeiectronic Systems

A. Potton: An Introduction to Digital Logic

G. Williams: An Introduction to Electrical Circuit Theory 


\section{Electronic Equipment Reliability}

\section{J. C. CLULEY}

Senior Lecturer in Electronic and Electrical Engineering University of Birmingham 
All rights reserved. No part of this publication may be reproduced or transmitted, in any form or by any means, without permission

\section{First published 1974 by \\ THE MACMILLAN PRESS LTD \\ London and Basingstoke Associated companies in New York Dublin Melbourne Johannesburg and Madras}

SBN 333152018

ISBN 978-1-349-02032-4 ISBN 978-1-349-02030-0 (eBook)

DOI 10.1007/978-1-349-02030-0

Library of Congress Catalog Card No. 74-8501

The paperback edition of this book is sold subject to the condition that it shall not, by way of trade or otherwise, be lent, re-sold, hired out, or otherwise circulated without the publisher's prior consent in any form of binding or cover other than that in which it is published and without a similar condition including this condition being imposed on the subsequent purchaser. 


\section{Contents}

Preface

ix

1 Introduction 1

1.1 Introduction 1

1.2 Historical survey 1

1.3 Definition of reliability 3

1.4 What is reliability worth? 4

1.5 Mean time between failures 7

1.6 The mean time to failure 8

$\begin{array}{llr}1.7 & \text { Availability } & 9\end{array}$

1.8 Unavailability or down-time ratio 11

1.9 The effect of environment 12

1.10 Generalised definitions of failure rate and MTBF 14

\section{The Mathematical Background 18}

2.1 Probability 18

2.2 The classical definition of probability 18

2.3 The relative frequency definition of probability 20

2.4 Complementary events 20

2.5 Compound events 21

2.6 Joint probability for non-exclusive events 23

2.7 General addition rule 26

2.8 Conditional probability 27

2.9 Bayes' theorem 29

2.10 Probability diagrams 33

2.11 Binomial distribution $\quad 34$

2.12 Examples of binomial distribution 39

2.13 The most probable outcome $\quad 42$

2.14 The Poisson distribution 43 
2.15 Examples of Poisson distribution 46

2.16 The exponential failure law 48

2.17 Statistics $\quad 51$

2.18 The mean $\quad 52$

2.19 Other measures of location $\quad 52$

2.20 Variability 53

2.21 The normal distribution $\quad 54$

3 Reliability Prediction 59

3.1 System subdivision $\quad 59$

3.2 Reliability models $\quad 59$

3.3 Failure analysis of series systems $\quad 61$

3.4 Example of series system 63

3.5 Parallel systems 65

3.6 Other parallel configurations 67

3.7 Example of parallel system 67

3.8 Analysis of mixed system $\quad 70$

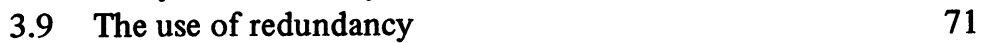

3.10 Temporal redundancy $\quad 72$

3.11 Error-correcting codes $\quad 75$

3.12 Multichannel redundancy 77

3.13 The level of redundancy $\quad 80$

3.14 Use of duplicate switching units 83

3.15 Triple redundancy 85

3.16 Comparison of duplicate and triplicate systems 86

3.17 Quadded logic $\quad 90$

3.18 MTBF of redundant systems 91

3.19 Approximate methods $\quad 94$

3.20 Effect of failure mode on design 95

4 Component Failure Data 98

4.1 Variation of failure rate with time 98

4.2 Types of failure 100

4.3 Factors affecting failure rate 102

4.4 The effect of temperature 103

4.5 Temperature and failure rate 104

4.6 Estimating internal temperature rise 107

4.7 The effect of voltage stress 109

$\begin{array}{lll}4.8 & \text { Environmental factors } & 110\end{array}$

4.9 The problem of measuring failure rates 111 
4.10 Confidence limits and confidence level

4.11 Evaluating test results

4.12 Sequential testing

4.13 Environmental testing of equipment

4.14 Screening and failure mode analysis

4.15 Screening tests

4.16 The demand for extreme reliability

\section{Designing for Reliability}

5.1 Aspects of reliability

5.2 The effect of tolerances

5.3 Worst-case design of switching circuits

5.4 The difficulties of worst-case design

5.5 Statistical design

5.6 Component selection

5.7 De-rating to improve reliability

5.8 Assessed quality components

5.9 Mechanical design

5.10 Protection against interference and noise

5.11 Using redundancy

5.12 Maintained and non-maintained systems 144

5.13 The use of fault indicators $\quad 145$

5.14 Digital fault indicators 147

5.15 Analogue redundancy 148

5.16 Parallel redundancy 149

5.17 'Fail-safe' circuits $\quad 152$

5.18 Future trends 155

Bibliography 157 


\section{Preface}

The first detailed studies of electronic equipment reliability were undertaken to improve the performance of communications and navigational systems used by the armed services. The techniques then developed were subsequently refined and applied to equipment used for many other applications where high reliability was of paramount importance, for example in civil airline electronic systems.

Developments in electronic technology during the last two decades have also caused increased interest in reliability. For example the digital computer has evolved from a rare and somewhat unreliable device into an essential management service for most large industrial and commercial concerns, and a central element in many process- and plant-control systems. Furthermore the introduction of solid-state devices and integrated circuits has so reduced the price of electronic equipment that systems of much greater complexity are now available at economic prices. As a result of the growing contributions of these systems to many industrial and commercial activities their reliability and availability have become of great interest to the equipment user, and much more attention is now paid to these qualities in system specifications.

There is thus a need for all engineers concerned with the design, testing or commissioning of electronic systems or the components from which they are assembled to understand the factors that influence reliability, the ways in which it can be measured and specified, and the means whereby it can be improved where necessary.

This book is designed to present such information at a level suitable for students in the final year of degree and diploma courses. This is considered to be the most suitable part of the course in which to introduce the subject of equipment reliability, since any detailed consideration of the topic requires some acquaintance with many aspects of electronic 
engineering. Among these are analogue and digital signal transmission and processing, circuit and system design, and component characteristics and tolerances. Although the material of the book is not developed to the level generally reached in postgraduate studies, it would be a suitable introduction to the subject, to be followed by a more detailed examination of particular topics.

Many of the calculations in the book involve simple application of the laws of probability and some knowledge of statistics. Since these topics are not included in all engineering mathematics courses a summary of the material is presented in chapter 2 . Apart from this the only mathematics required are elementary algebra and simple integration.

Copies of the British Standards mentioned in the text can be obtained from the British Standards Institution, Sales Branch, 101 Pentonville Road, London N1 9ND. 